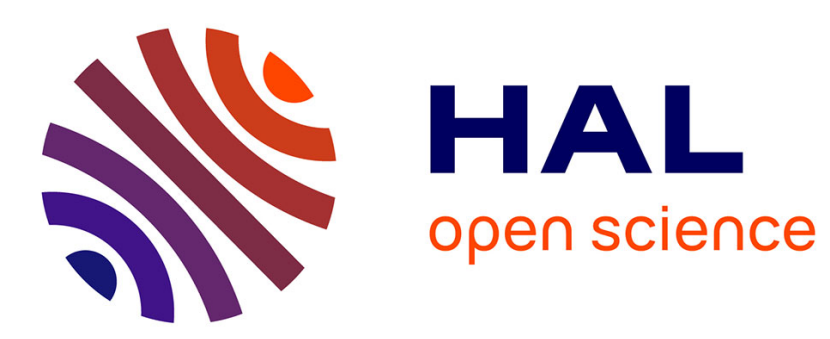

\title{
Dangers on the road: A longitudinal examination of passenger-initiated violence against bus drivers
}

\author{
Biru Zhou, Richard Boyer, Stéphane Guay
}

\section{To cite this version:}

Biru Zhou, Richard Boyer, Stéphane Guay. Dangers on the road: A longitudinal examination of passenger-initiated violence against bus drivers. Stress and Health, 2017, 10.1002/smi.2779 . hal01626445

\section{HAL Id: hal-01626445 \\ https://hal.science/hal-01626445}

Submitted on 30 Oct 2017

HAL is a multi-disciplinary open access archive for the deposit and dissemination of scientific research documents, whether they are published or not. The documents may come from teaching and research institutions in France or abroad, or from public or private research centers.
L'archive ouverte pluridisciplinaire HAL, est destinée au dépôt et à la diffusion de documents scientifiques de niveau recherche, publiés ou non, émanant des établissements d'enseignement et de recherche français ou étrangers, des laboratoires publics ou privés. 
Dangers on the Road: A Longitudinal Examination of Passenger Initiated Violence Against Bus Drivers

\title{
Biru Zhou
}

Centre for Research on Children and Families, McGill University

and

Trauma Studies Centre, Institut universitaire en santé mentale de Montréal

\author{
Richard Boyer \\ Department of Psychiatry, Université de Montréal \\ and \\ Institut universitaire en santé mentale de Montréal \\ Stéphane Guay \\ School of Criminology, Université de Montréal \\ and
}

Trauma Studies Centre, Institut universitaire en santé mentale de Montréal 
Corresponding authors: Biru Zhou, Ph.D. (biru.zhou@mcgill.ca; 1(514)398-5649; Fax: 1(514)-398-5287) and Stéphane Guay, Ph.D. (stephane.guay@umontreal.ca; 1(514)251-4000, ext. 3084; Fax: 1(514)251-4014).

Acknowledgement: This project was supported in part by a team grant from the Canadian Institutes of Health Research (TVG 89969). The authors would also like to thank Charles-Edouard Giguere for his insightful comments and suggestions on our statistical analyses in this project. 


\begin{abstract}
This study examined the impact of workplace violence against 109 bus drivers over a one-year span. Workplace violence is related to both psychological and work related consequences. Our findings showed that bus drivers experienced a wide range of violence at work and the psychological consequences were devastating: half of the participants met the diagnostic criteria for acute stress disorder within the first month following the index event. Majority of them experienced at least moderate levels of PTSD problems over the one year span. About $9.3 \%$ of participants showed a delayed onset of PTSD six months after. Furthermore, counter-supportive behaviours and re-exposure to violence played important roles in the maintenance of PTSD symptoms over time. Even though PTSD symptoms per se did not relate to bus driver's confidence in coping with aggressive passengers, the immediate posttraumatic reaction - symptoms of acute stress disorder - showed a significant long term negative effect on bus drivers' confidence in dealing with aggressive passengers 12 months after. This study provided empirical evidence of the changing nature of PTSD symptoms over time among bus drivers.

Keywords: Workplace Aggression, Violence, PTSD, Acute Stress Disorder, Social Support, Work Confidence
\end{abstract}


Dangers on the Road: A Longitudinal Examination of Passenger Initiated Violence Against Bus Drivers

On March 23rd, 2015 the Department of Justice Canada joined by the Canadian Senator Bob Runciman to celebrate Bill S-221, which amends the Criminal Code of Canada to make assaults against on duty public transport operators (e.g., drivers for bus, minibus, trolley and taxi) an aggravating circumstance in sentencing (The Department of Justice Canada, 2015). While the justice system has taken clear actions against violence towards public transit operators, research on violence against bus drivers are also considered as imperative in academia.

Public transit operators' safety and well-being are closely interlocked with millions of passengers' and other road users' safety and well-being on a daily basis. However, international research had painted a terrifying picture of what public transit operators had to face at work everyday. Every year, there are about 2000 assaults against transit employees reported in Canada (Canadian Urban Transit Assocation, 2014). The majority of these assaults $(75 \%)$ occur on transit vehicles, whereas $15 \%$ occur in transit stations. These assaults include littering, causing damage to the vehicle, throwing objects to the operator, verbal threats, physical assaults with or without weapons, and sexual assaults. This malevolence against bus drivers is far from unique in Canada. Lincoln and Gregory (2015) used a multi-method study to show that Australian bus drivers were suffering from very similar types of violence on the job, and the majority of bus drivers had experienced some form of passenger abuse (i.e., physical violence/antisocial behaviours/incivility) in the past 12 months. Couto and Lawoko (2011) also reported that more than three-quarters of the public transit drivers had experienced workplace violence in their life time and more than two-thirds had been a victim of workplace violence in the past 12 months. Strikingly similar phenomena were reported also in UK (Smith \& Cornish, 2006), Brazil (Sampaio, Coelho, Barbosa, Mancini, \& Parreira, 2009), Lithuania (Obelenis, Gedgaudiene, \& Vasilavicius, 2003), and Norway (Glaso, Bele, Nielsen, \& Einarsen, 2011). These past research on 
workplace violence against public transit operators all point to the conclusion that driving a bus is a very stressful and high risk occupation (Kompier, Aust, van den Berg, \& Siegrist, 2000; Tse, Flin, \& Mearns, 2006).

Bus drivers often work alone, involve in cash handling procedures, work in tight schedules and irregular hours, have direct contact with a large public in an overcrowded space, and often encounter passengers who are intoxicated (Essenberg, 2003; Tse et al., 2006). All of the above job characteristics of bus drivers are related to high risks of harassments and violence. Previous research consistently show that workplace violence in the service sector is detrimental to workers' physical and mental health (e.g., Dupré, Dawe, \& Barling, 2014; Guay, Goncalves, \& Jarvis, 2014; Hershcovis \& Barling, 2007; LeBlanc \& Barling, 2005; Vedantham et al., 2001). The "possibility of assault" was reported by UK bus drivers as their top psychosocial stressor at work (Duffy \& McGoldrick, 1990). More recent findings continued to support that the risk of being assaulted on the job was still a major concern among public transport workers (Budd, 2001). The stressful work environment combined with the challenging job demands could make any negative interactions with passengers easily escalate to a much more serious situation (e.g., G. W. Evans \& Johansson, 1998).

Even though some researchers suggest that psychological distress in the form of post-traumatic stress disorder (PTSD) may be rare for bus drivers (Tse et al., 2006), the prevalence rate for developing PTSD among bus drivers exposed to traumatic events at work (about 10.7\%; Boyer \& Brunet, 1996) was higher than the general population in the U.S. (about 6.8\%; Kessler et al., 2005) and comparable with the life time prevalence rate in Canada (9.2\%; Van Ameringen, Mancini, Patterson, \& Boyle, 2008). Moreover, PTSD is not only detrimental to bus drivers' psychological well-being and physical health (Tse et al., 2006; Vedantham et al., 2001), it can also interfere with victims' normal emotional functioning on a day to day basis (Kunst \& Winkel, 2013), which may influence bus drivers' work performance. Therefore, the examination of PTSD among bus drivers is of major interests among the general public and public transport organizations. 


\section{PTSD and Social Support}

PTSD is a chronic mental illness that may develop among victims (or witnesses) exposed to traumatic event(s). It is characterized by victims (or witnesses) of trauma experiencing intrusive thoughts (e.g., nightmares or difficulties concentrating), avoidance behaviours (e.g., avoiding activities that might remind them of the trauma), negative alterations in cognition and mood (e.g., persistent and distorted blame of self or others, and persistent negative emotional state), as well as alterations in arousal and reactivity (e.g., reckless or self-destructive behaviours, hypervigilance and exaggerated startle responses; American Psychiatric Association, 2013). Empirical evidence showed that social support could have buffering effects on PTSD (Adams \& Boscarino, 2006; Andrews, Brewin, \& Rose, 2003; Avery \& McDevitt-Murphy, 2014; Guay, Billette, \& Marchand, 2006; Guay et al., 2011; Laffaye, Cavella, Drescher, \& Rosen, 2008; Pietrzak et al., 2010; Schnurr, Lunney, \& Sengupta, 2004). Specifically, lack of social support after the traumatic event is one of the strongest social factors that predicts PTSD. Individuals with lower levels of social support after a traumatic event reported higher levels of PTSD symptoms (Brewin, Andrews, \& Valentine, 2000; Ozer, Best, Lipsey, \& Weiss, 2008).

Joseph, Williams, and Yule (1997) in their research suggested that social support could affect PTSD symptoms directly and indirectly. In the direct route, social interactions can affect individuals' psyche on their emotions, cognitions and symptoms. Significant other's point of the view on the traumatic event can influence victim's own interpretations of the event (positively or negatively) and consequently impact symptoms of PTSD (Joseph et al., 1997). This is consistent with the Interdependence Theory in the field of social relations that members within a close relationship often influence each others' emotions, cognitions and behaviours (Rusbult \& Van Lange, 2008; Wickham \& Knee, 2012). Evidence from previous research supported this direct route, suggesting that perceived social support was negatively associated with PTSD severity (e.g., Adams \& Boscarino, 2006; Avery \& McDevitt-Murphy, 2014; Pietrzak et al., 2010). 
Furthermore, according to Joseph et al. (1997), social support could also influence PTSD indirectly by changing individuals' ways of coping after the trauma. Although social support usually refers to the positive aspects of social interactions, close relationships are also comprised of negative interactions that are counter-supportive. For instance, people can provide poor advice (Shumaker \& Hill, 1991) or simply engage in negative behaviours, such as criticism, complains, refusal to help, or making hurtful and insensitive remarks of the situation (Crevier, Marchand, Nachar, \& Guay, 2014; Cutrona \& Suhr, 1994). These unhelpful and counter-supportive behaviours from significant others could indirectly contribute to the development and maintenance of PTSD symptoms. Victims encountering negative interactions with their significant others might engage in more avoidance behaviours (e.g., avoid thinking about the event or avoid disclosing feelings to others). Eventually, these negative interactions would lead to slower recovery or even greater psychological distress (Guay et al., 2006; Joseph et al., 1997). In short, helpful, uncritical and sensible support has positive impact on the path to recovery, whereas counter-supportive and critical responses are detrimental to trauma survivors.

Although previous research acknowledge that social support is an important buffer of stress among bus drivers (Tse et al., 2006), the existing research on the influences of social support among bus drivers are limited in scope (e.g., French et al., 2010; Sampaio et al., 2009). In particular, previous research focused primarily on social support at work provided by co-workers and supervisors (Sampaio et al., 2009; Tse et al., 2006). Since bus drivers often work alone and lack opportunities to interact with other co-workers on the job, it is important to examine how social support from non-work settings (e.g., friends and family) could buffer stress, especially for the ones who are experiencing symptoms of PTSD after encountering severe violence at work.

\section{Occupational Consequence of PTSD}

PTSD is a serious mental health issue among trauma victims. It can negatively impact work functioning, such as absenteeism, unemployment, and work disability, regardless 
whether it is full PTSD or partial PTSD (Breslau, Lucia, \& Davis, 2004; Matthews \& Chinnery, 2005; Taylor, Wald, \& Asmundson, 2006; Zlotnick, Franklin, \& Zimmerman, 2002). Previous research showed that symptoms of PTSD, particularly the symptom of hypervigilance, could interfere with normal emotional functioning (Kunst \& Winkel, 2013). The tendency to look for emerging dangers excessively is often accompanied by misinterpretations and negative appraisals of non-threatening cues in the environment among PTSD patients. This dysfunctional emotional reaction due to PTSD could be very problematic for bus drivers when dealing with difficult passengers. Bus drivers might misinterpret non-threatening cues as dangerous and then react irritably and even aggressively (e.g., exaggerated startle responses; American Psychiatric Association, 2013; Kunst, Winkel, \& Bogaerts, 2011).

Reduced concentration at work triggered by PTSD symptoms could also lead to misinterpretations of non-threatening cues in the environment (Work Safe BC, n.d.). This self-precipitating hypervigilant reaction under the influence of PTSD symptoms may severely compromise bus drivers' occupational functioning (S. Evans, Giosan, Patt, Spielman, \& Difede, 2006; Work Safe BC, n.d.). Instead of diffusing a potentially dangerous event, the inappropriate or exaggerated startle reactions stemming from PTSD symptoms could intensify a dangerous event while dealing with difficult passengers. Hence, it is essential to examine bus drivers' self perceived confidence in coping with potentially aggressive passengers as an occupational consequence of PTSD.

\section{The Current Study}

The objective of this study is to examine psychological consequences of severe violence against bus drivers and to test the buffering effects of social support on PTSD symptoms longitudinally in a one-year span. These research focuses were addressed using a 4-wave longitudinal design spanning over 12 months to follow bus drivers who had encountered a violent event at work. The use of a longitudinal design was necessary in order to capture the 
changes and dynamics underlying the psychological and occupational consequences of workplace violence over time.

Prior to developing symptoms of PTSD, victims of traumatic event often experience an anxiety disorder - acute stress disorder (ASD; e.g., Bryant, Moulds, \& Guthrie, 2000; Harvey \& Bryant, 2000). ASD describes a set of very intense posttraumatic reactions within the first month following the event. Previous research found that ASD diagnosis is strongly predictive of later PTSD diagnosis (Brewin, Andrews, Rose, \& Kirk, 1999; Bryant et al., 2000; Bryant \& Harvey, 2003; Cahill, Pontoski, \& D’Olio, 2005). Therefore, ASD must be accounted for in order to better understand changes in PTSD over time.

In this study, we examined what specific patterns of social support (supportive versus counter-supportive) were associated with changes in PTSD symptoms over time. It was hypothesized that (1) supportive behaviours were associated with a general decline of PTSD symptoms over time, whereas (2) counter-supportive behaviours were positively associated with PTSD symptoms over time, after controlling for symptoms of acute stress disorder and demographic information, such as gender, age and marital status, etc. In this study, we also investigated bus drivers' confidence in coping with aggressive passengers one year after the violent incident. (3) It was hypothesized that high levels of acute stress disorder symptoms after the violent event were related to lower levels of bus drivers' confidence in coping with aggressive passengers one year later. (4) Similarly, PTSD symptoms one month, six and twelve months after the violent event would negatively relate to bus drivers' confidence in coping with aggressive passengers one year later.

\section{Method}

\section{Participants}

This study was part of a bigger project investigating better management of workplace violence among employees of a public transit company. The data used in this study consisted of 109 bus drivers (women $=46$, men $=63$ ) who had recently filed a work incident report 
regarding a violent event at work. This reported violent work incident is referred to as the index event in this study. Among the 109 participants in our study, about $60.6 \%$ were married or in a common-law relationship. Most of them were working in night shifts, over night shifts or on rotation. Furthermore, due to the index event, some of the participants were on sick leave during our four assessments (35.8\% of participants at Time 1, $14.7 \%$ at Time $2,6.5 \%$ at Time 3 and $5.8 \%$ at Time 4$)$.

\section{Procedure}

The union representatives and human resources staffs first approached the participants, who recently filed an incident report about a violent event at work, by providing them with a brief description of our study. Potential participants were asked whether they would be interested in participating in our one year study. Interested participants were then asked to sign an authorization form to leave their contact information for our research coordinators to contact them after. The completed contact authorization forms were forwarded to the research team immediately and potential participants were called in the following days to see if they agreed to participate in the study. A packet of questionnaires along with a consent form were sent to the participants who agreed to participate in the study four times by mail following the index event. Questionnaires and the consent form once completed and signed were sent back to our research center by mail. Time 1 assessment was scheduled within 2 to 4 weeks following the index event, Time 2 assessment was scheduled for 1 month after the index event, Time 3 assessment was scheduled for 6 months after and Time 4 was scheduled for 12 months after the index event.

A compensation of 25 Canadian dollars were sent to the participants who completed the questionnaires at each time of assessment. In addition, the public transit company paid a compensation equivalent to 4 hours of wages to bus drivers who have completed the entire study - all four times of assessments. The list of participants who completed the entire study was sent to the heads of the company at the end of the project so that participants can 
receive the compensation from their employer. This project was conducted between 2013 -2015. A total of 109 participants completed the Time 1 questionnaire, 109 participants returned to complete the Time 2 questionnaire, 108 returned for the Time 3 questionnaire, and 104 returned for the Time 4 questionnaire. This study was approved by the ethics committee in our research institute, and participants were informed prior to the study that their participation was completely voluntary and they could drop out from the study at any time without any penalty.

\section{Measures}

Social Support. The perceived social support was measured using the Questionnaire on Social Support Behaviours in Anxious Situations (Guay et al., 2011). This scale is a 30-item self-report questionnaire assessing perceived frequencies of supportive social interactions (9 items) and counter-supportive social interactions (22 items) with one identified significant other on a 5 -point Likert-type scale ranging from $1=$ "Never" to $5=$ "Always". Examples of the supportive social interactions include when the significant other "asks me how I feel", or "gives me advice". Examples of counter-supportive interactions include when the significant other "criticizes the way I react", or "makes me feel guilty". The one significant other identified by participants in our study included spouse, family members or friends. The average Cronbach's $\alpha$ was .89 across four time points for the supportive social interactions scale, and the average Cronbach's $\alpha$ was .90 across four time points for the counter-supportive social interactions scale.

Psychological consequences of violence. The Acute Stress Disorder Scale (ASDS; Bryant et al., 2000) was used for Time 1 assessment to measure the immediate psychological consequences of the index event at work. This scale was designed to identify acute posttraumatic stress reactions preceding the potential development of PTSD. This scale consists of 19 items that describe symptoms of acute stress disorder. Each symptom was presented on a 5-point scale ranging from $1=$ "Not at all" to $5=$ "Very much". An 
example of the scale includes "Do you feel very upset when you are reminded of the trauma?" Cronbach's $\alpha=.87$ was obtained for this scale in this study.

The Time 2 to Time 4 assessments on psychological consequences were administered using the PTSD Checklist (PCL; Bliese et al., 2008; Weathers, Litz, Herman, Huska, \& Keane, 1993). $\mathrm{PCL}^{1}$ is a 17 -item self assessment of symptoms of PTSD in the fourth edition of the Diagnostic and Statistical Manual of Mental Disorder (DSM-4; American Psychiatric Association, 1994). This scale can be used for monitoring symptom changes over time, screening for PTSD and making provisional PTSD diagnosis. Each symptom was presented on a 5 -point scale ranging from $1=$ "Not at all" to $5=$ "Extremely". An example of the items includes "In the past month, how much were you bothered by repeated, disturbing, and unwanted memories of the stressful experience?" The average Cronbach's $\alpha$ was .94 across three time points for this scale in this study.

Confidence in Coping with Aggressive Passengers. Bus drivers' confidence in coping with aggressive passengers was measured by the adapted version of "Confidence in Coping with Patient Aggression Instrument" (CCPAI; Thackrey, 1987), which was originally designed to assess clinicians' self-perceived ability, preparation, and comfort in safety and efficiency for intervening psychologically and physically with aggressive patients. This scale has been widely used in the healthcare sector (e.g., Martin \& Daffern, 2006; Verhaeghe et al., 2014). This instrument consists of 10 items measuring different constructs associated with service provider's confidence on a 11-point linear scale. A Cronbach's $\alpha$ of .93 at Time 4 assessment (i.e., one year after the index event) was obtained for this scale in the present study. Example items are as follows:

How comfortable are you working with an aggressive service user? (1 = very uncomfortable to $11=$ very comfortable)

How safe do you feel around an aggressive service user? (1 = very unsafe to 11 = very

\footnotetext{
${ }^{1}$ PTSD Checklist for DSM-5 (PCL-5) was not used in this study because PCL-5 was not published when we first launched our study. In order to have consistent measures throughout our study, we have decided to keep using PCL even after PCL-5 became available.
} 
safe)

Demographic information. Demographic information, such as age, gender $(0=$ male, $1=$ female $)$ and marital status $(0=$ not married and not common-law, $1=$ married or common-law) were assessed at Time 1 only. According to previous research on workplace violence against bus drivers and other occupations, working on day shifts $(0=$ other shifts, 1 = day shifts) could be a protective factor against workplace violence (e.g., Gilbert, 2011; Harrell, 2011; Guay et al., 2014; Mayhew, 2000; Tse et al., 2006). Work shifts were measured at all four assessments. Moreover, studies on trauma and PTSD suggest that prior exposure to trauma and repeated exposure to violence after a trauma are positively related to higher levels of PTSD (e.g., Adams \& Boscarino, 2006; Brunet, Boyer, Brillon, Ehrensaft, \& Stephenson, 1998; Brunet, Boyer, Weiss, \& Marmar, 2001; Schnurr et al., 2004). Therefore, the number of violent events encountered by bus drivers at work (being a victim or a witness) prior to the index event was measured at Time 1. Repeated exposure to violent events $(0=$ No, $1=$ Yes $)$ after the index event was measured at Time 2, 3 and 4 assessments. All demographic variables were included as control variables in our analyses.

\section{Results}

In this section, we will first report results on descriptive statistics pertaining the nature of the violence encountered by bus drivers at work, and percentages for ASD and PTSD diagnosis in our sample. The effects of social supportive and counter-supportive behaviours on changes of PTSD symptoms over time will be analyzed using linear mixed effect models. Total scores of supportive social interactions scale, counter-supportive interactions scale, ASDS, PCL and CCPAI were used for all analyses. All continuous predictors were grand mean centered before entering into the longitudinal analysis, unless otherwise specified.

\section{Descriptive Statistics}

Participants in our study had reported a wide range of violence they experienced at work, including physical (20.2\%; e.g., being spat on or punched, threatened at gun point, 
sexual harassment, etc.), verbal (35.8\%; e.g., intimidation, insults, death threats, etc.), both physical and verbal (24.8\%; e.g., being spilled hot coffee on the lap with insults), verbal aggression with physical aggression towards objects $(13.8 \%$; e.g., damaging the bus with insults), physical aggression towards objects $(1.8 \%$; e.g., gun shots fired on the bus but not towards the bus driver), witnessing physical or verbal aggression on the bus $(2.8 \%$; e.g., witnessed a severe physical assaults against another passenger), and theft (0.9\%; personal belongings being stolen). Participants also indicated they had experienced or witnessed on average 5.48 incidents of violence (ranging from 2 to 22 incidents) at work prior to the index event. Previous exposure to violent events at work appears to be very common among bus drivers in our study.

Within the first month following the index event, more than half of our participants $(58.7 \%)$ met the diagnostic criteria for acute stress disorder (Bryant et al., 2000). About $17.4 \%$ of participants met the full diagnostic criteria for PTSD $^{2}$ (Weathers et al., 1993), with an additional $22.9 \%$ of participants reported significant problems in PTSD symptoms which can be described as experiencing "partial" PTSD (PCL scores higher than 32; Dickstein et al., 2014) one month after the index event. Please see Table 1 for percentages of participants meeting different diagnostic criteria across the four time points.

\section{Insert [Table 1] here.}

Gender variations were examined for different diagnostic criteria. Results showed that men were more likely to experience moderate problems of PTSD (i.e., moderate level of symptom endorsement in at least one diagnostic cluster measured in PCL) than women one month after the index event, $\chi^{2}(1)=4.22, p=0.04$. No other significant gender differences were observed in our analyses (see Table 1). It has been well documented that women appear to suffer from PTSD more frequently and more intensively than men (Brewin et al., 2000; Gradus, 2016), even after controlling for frequency of exposure and types of violence

\footnotetext{
${ }^{2}$ Full PTSD diagnosis was given when participant had endorsed at least 1 item in cluster B, at least 3 items in cluster C, at least 2 items in cluster D, and obtained a total PCL score greater than 44. A response greater than 2 was considered an endorsement towards an item (Weathers et al., 1993).
} 
(e.g., Stein, Walker, \& Forde, 2000; Tolin \& Foa, 2006). However, due to the lack of gender differences on PTSD symptoms observed in this study and lack of gender differences on psychological distress among bus drivers in previous research (e.g., Rydstedt, Johansson, \& Evans, 1998), the following analyses would not focus on gender differences in PTSD but would enter gender as a control variable along with other demographic variables. Table 2 presents correlations across all variables.

Insert [Table 2] here.

Furthermore, there were 10 participants (9.2\%) showed a delayed onset of full PTSD six months after the index event, and only three participants had full PTSD persisted through Time 2 to Time 4 assessments. The severity of PTSD symptoms appeared to vary within the first 12 months following the index event. Therefore, a longitudinal approach is most appropriate for a thorough understanding of the effects of social support on changes in PTSD symptoms over time.

\section{Social Support and PTSD}

Due to the longitudinal design of the study, linear mixed effect models using SAS version 9.3 were employed in the following analyses. Four models in the longitudinal analysis of PTSD symptoms over a one-year span were conducted: Model A was the intercept only model to access whether individuals' PTSD symptoms measured by PCL changed over time; Model B was a conditional model with supportive behaviours (or counter-supportive behaviours) and time as predictors controlling for levels of acute stress disorder measured by ASDS; Model $\mathrm{C}$ was the interaction model where the interaction of supportive behaviours (or counter-supportive behaviours) and Time was entered in the model controlling for the levels of acute stress disorder; Model D was the final model with ASDS and all demographic information (i.e., age, gender, marital status, work shifts, prior and repeated exposure) entered as control variables. 
According to our preliminary analysis on collinearity, supportive and counter-supportive behaviours were highly correlated (ranged between -.40 to -.51; see Table 2 ), and the variance inflation factors for supportive and counter-supportive behaviours ranged between 1.93 to 4.54, which indicated a moderate to serious concern for collinearity. Previous research also showed distinct and independent impact of supportive versus counter-supportive behaviours on PTSD (e.g., Abbey, Abramis, \& Caplan, 1985; Andrews et al., 2003; Borja, Callahan, \& Long, 2006). As a result, supportive and counter-supportive behaviours were entered in separate models for the analyses ${ }^{3}$. All longitudinal analyses conducted in this study followed the procedures recommended by Singer and Willett (2003).

Insert [Table 3] here.

Supportive Behaviours on PTSD. Table 3 presents the mixed effect estimates for all the models analyzed in this study. The intercept variance $\left(\sigma_{0}^{2}=31.96, p=.003\right)$ and the residual variance $\left(\sigma_{\varepsilon}^{2}=135.31, p<.001\right)$ in Model A indicated that there were significant between-person and within-person variations in PTSD. ICC calculated based on estimates obtained in Model A showed that there were 19.1\% of between-person variations in the model. Thus, it is advantageous to use linear mixed effect models to examine the changes in PTSD in order to capture both the within- and between-person variations over time (Singer \& Willett, 2003).

Results from Model B showed that there were significant differences among individual bus drivers' initial levels of PTSD at four weeks after the index event and their levels of PTSD changed significantly over time. There was a general decline of PTSD levels over time, suggested by the negative coefficients of Time in all the models. However, supportive behaviours provided by bus driver's significant other did not relate to the changes in PTSD, as shown in Models B and C. The interaction between supportive behaviours and Time was

\footnotetext{
${ }^{3}$ Only random intercept models were presented here in this study because they were the most parsimonious models in comparison with random slope models. The same sets of analyses were conducted with random slopes entered in Models B, C and D. No significant changes of the results were obtained except the goodness of fit decreased in the random slope models.
} 
not significant in Model D either. In other words, the changes in PTSD over time did not depend on the levels of supportive behaviours. Among the control variables, acute stress disorder and repeated exposure to violence significantly predicted higher levels of PTSD.

Counter-Supportive Behaviours on PTSD. Different results were obtained in the analyses regarding the influences of counter-supportive behaviours. Counter-supportive behaviours were positively related to PTSD symptoms (Models B, C and D), and the interaction between counter-supportive behaviours and Time was significant in Model D. The significant interaction suggested that the weekly rate of change in PTSD symptoms over time differed depending on the levels of counter-supportive behaviours individual bus drivers reported (see Figure 1). More specifically, bus drivers who reported high levels of counter-supportive behaviours from their confidant at 4 weeks after the index event, rated higher on PCL than those reported low levels of counter-supportive behaviours. Furthermore, over the 12 months period of our study, the impact of counter-supportive behaviours on PTSD levels, though destructive, faded away much faster for the ones who received high levels of counter-supportive behaviours from their significant others than the ones who received low levels of counter-supportive behaviours. Similar patterns of control variables emerged in the analyses of counter-supportive behaviours. Acute stress disorder and repeated exposure to violence also significantly predicted higher levels of PTSD symptoms in Model D.

Insert [Figure 1] here.

\section{Negative Influences of PTSD on Driver's Confidence}

In order to test the long term effect of posttraumatic reactions to workplace violence among bus drivers, we entered the levels of acute stress disorder, and levels of PTSD at each time point to predict bus drivers' confidence in dealing with aggressive passengers 12 months after the index event. A multiple regression using SPSS version 22 was used for this analysis. Gender was entered in the regression model as a control variable ${ }^{4}$. Results showed that even

\footnotetext{
${ }^{4}$ During a preliminary analyses, all demographic variables were entered in the regression model. However, all the demographic variables were not significant, and did not improve the model fit, except gender. Therefore,
} 
though levels of PTSD symptoms over time did not directly impact bus drivers' confidence in coping with aggressive passengers, bus drivers' immediate acute stress reaction within the first month following the index event significantly predicted lower levels of confidence in bus drivers 12 months after (see Table 4). Furthermore, the significant gender differences in the regression model indicated that female bus drivers were less confident in dealing with aggressive passengers than male bus drivers. These results indicated that workplace violence not only had immediate psychological effects on bus drivers but also had long term negative influences at work functioning.

Insert [Table 4] here.

\section{Discussion}

Workplace violence has detrimental effects on workers' mental health and well-being, and its devastating consequences on workers' lives can no longer be overlooked (e.g., Barling, Dupré, \& Kelloway, 2009; Banyard, Potter, \& Turner, 2011; Couto \& Lawoko, 2011; Gates, Gillespie, \& Succop, 2011; Gilbert, 2011; Health and Safty Executive, 2015; Lanctôt \& Guay, 2014; Lincoln \& Gregory, 2015; Tse et al., 2006). This study used a longitudinal approach to examine the psychological and work consequences of workplace violence among a group of bus drivers. Our results showed that bus drivers experienced a variety of terrifying workplace violence ranging from frightful verbal abuse from passengers to death threats at gun point. Similar to previous research (e.g., Brunet et al., 1998; Glaso et al., 2011; Obelenis et al., 2003; Tse et al., 2006), workplace violence is a common phenomenon experienced by bus drivers in our sample.

Exposure to workplace violence can severely jeopardize bus drivers' mental health. According to our analysis (Table 1), more than half of the bus drivers were experiencing acute stress disorder, and the majority of them (84.3\%) went on to experience at least moderate levels of PTSD symptoms one month after. More strikingly, almost half of the bus we presented the most parsimonious model with gender as a control variable in this analysis. 
drivers continued to suffer at least moderate levels of problems in PTSD 12 months after. The maintenance of PTSD symptoms among bus drivers may be due to their continued exposure to a working environment (i.e., on the bus) where the original traumatic event took place (Lerias \& Byrne, 2003). The familiar workplace might serve as a vivid reminder of the violent event for the victims and prompt them to constantly relive the violence at work, which then contributes to the maintenance of PTSD over time.

Moreover, repeated exposure to violence after the the original index event could be related not only to the maintenance of PTSD symptoms, but also to the development of the delayed onset of PTSD. In our sample, there were 10 drivers who met the full PTSD diagnosis 6 months after the index event. A post hoc examination of these 10 bus drivers showed that six of them had been exposed to violent events again after the original index event. Since our participants all had prior exposure to violence at work, they might have a recrudescence of PTSD symptoms triggered by the index event or by the re-exposure to violence after the index event (Adams \& Boscarino, 2006; Yehuda, 2002). The high possibility of encountering violence at work could place bus drivers in extreme risks of developing and maintaining PTSD symptoms in this occupation.

Social support is often considered a protective factor for PTSD after a traumatic event (Adams \& Boscarino, 2006; Andrews et al., 2003; Avery \& McDevitt-Murphy, 2014; Brewin et al., 2000; Crevier et al., 2014; Laffaye et al., 2008). We contended that while supportive behaviours could help alleviating symptoms of PTSD, counter-supportive behaviours could have adverse effects on PTSD symptoms (Clapp \& Gayle Beck, 2009; Guay et al., 2006, 2011; Lakey, Tardiff, \& Drew, 1994). According to our analyses, supportive behaviours were not related to changes in PTSD symptoms over time, nor was it related to levels of PTSD symptoms at each assessment. It is possible that the presence of supportive behaviours per se does not directly contribute to the decline of PTSD symptoms, but the complete lack of support or complete social isolation might have more detrimental effects on PTSD (e.g., Adams \& Boscarino, 2006; Avery \& McDevitt-Murphy, 2014; Brewin et al., 2000). 
In contrast, counter-supportive behaviours have significant impact on PTSD according to our analysis. Even though levels of PTSD symptoms decreased over time in our study, individuals who reported high levels of perceived counter-supportive behaviours rated higher on their PTSD symptoms at each assessment than those who reported low levels of counter-supportive behaviours. This adverse impact of counter-supportive behaviours on PTSD faded away over a one-year span. People who received high levels of counter-supportive behaviours from significant others initially would reach the same levels of PTSD symptoms one year after as those who received low levels of counter-supportive behaviours initially. In other words, the presence of counter-supportive behaviours may have contributed to the persistence of PTSD symptoms during the first year after the violent event.

PTSD and workplace violence have great impact on individuals' psychological well-being. Epidemiological studies showed that men were more reluctant to seek help in times of duress. Support from family members were more important to men's than to women's well-being because women were able to draw multiple sources of support (e.g., friends, families, religious affiliations, etc.; Cable, Bartley, Chandola, \& Sacker, 2012; Galdas, Cheater, \& Marshall, 2005). It is crucial for victims of workplace violence, especially for men, to draw on support from multiple sources and engage in direct support seeking (Barbee et al., 1993) indicating clearly what kind of support is needed in order to avoid the mismatch between support seeking and support provision (Cutrona, Shaffer, Wesner, \& Gardner, 2007).

Violence against bus drivers not only can lead to serious psychological distress, but it can also negatively influence bus drivers' confidence in coping with passenger aggression one year after, especially among female drivers. This study provided evidence for the long term effect of psychological distress on bus drivers' confidence in coping with aggressive passengers. After being exposed to a trauma, it is common for victims to experience a wide range of negative emotions, such as fear and anxiety, especially among female victims (e.g., Bryant \& Harvey, 2003). These negative emotions could hinder bus drivers' confidence in 
dealing with aggressive passengers effectively due to their reduced awareness and intensified fear of the surroundings, as well as heightened startle responses (Work Safe BC, n.d.). Even though there was no evidence suggesting gender differences on acute stress disorder or PTSD (except moderate levels of PTSD) in our sample, the significant gender effect on bus drivers' confidence in coping with aggressive passengers one year later may point to an indirect effect of PTSD on work consequences among bus drivers. In other words, gender differences of work consequences (e.g., confidence in coping with aggressive passengers) after a traumatic event might be transmitted through the effect of PTSD symptoms. Given the job characteristics of bus drivers (e.g., working along and highly stressful; G. W. Evans \& Johansson, 1998), their ability and confidence to cope with aggressive passengers are not only related to bus drivers' own safety but also other passengers and road users' safety. Therefore, it is essential to conduct more longitudinal studies to provide further comprehensive evidence of long term psychological and work related consequences of workplace violence among bus drivers.

\section{Conclusions, Limitations and Implications}

Our findings in this study supported previous research that workplace violence against bus drivers is not only a common phenomenon but also a repeated phenomenon (Boyer \& Brunet, 1996; Brunet et al., 1998; Couto \& Lawoko, 2011; Glaso et al., 2011; Lincoln \& Gregory, 2015; Smith \& Cornish, 2006; Tse et al., 2006), and it had short term and long term effects on individuals' mental health. It is important to have some social support after the traumatic event, but having low levels of counter-supportive interactions with significant

others is even more potent for the well-being of the victims. A subset of participants (9.2\%) shows a delayed onset of PTSD 6 months after, which provides empirical evidence of the changing nature of PTSD symptoms among bus drivers who are victims of workplace violence. Without the longitudinal design of the study, this interesting finding of delayed onset of PTSD would have been lost in a cross-sectional design.

Due to collinearity issues among supportive versus counter-supportive behaviours, it 
was not possible to analyze these two aspects of social support simultaneously in the same analytical model in the current study. Moreover, all participants in this study were able to identify a confidant from whom they have been receiving support since the index event. As a result, the measure for social support used in this study was not able to capture someone who had no social support available to them at all (i.e., complete lack of social support). Furthermore, we did not distinguish sources of support in this study, such as spousal support versus friend support. Laffaye et al. (2008) examined different sources of support among a group of male veterans with PTSD and found that veteran peer support was the most important, stress-free and highly valued component of the support resources for veterans, in comparison to family or non-veteran peer support. Our null finding of the positive social support on changes of PTSD symptoms could attest to the importance of considering social support and PTSD symptoms according to the sources of the support provider in future studies.

Gender differences on PTSD were not observed in our sample, which is seemingly contradictory with previous research on gender differences of PTSD (e.g., Andrews et al., 2003; Bryant \& Harvey, 2003; Olff, Langeland, Draijer, \& Gersons, 2007; Van Ameringen et al., 2008). However, the lack of gender differences on PTSD have been observed among traditionally male dominant professions, such as military or law enforcement (e.g., Brewin et al., 2000; Lilly, Pole, Best, Metzler, \& Marmar, 2009; Pole et al., 2001). The organizational culture that is traditionally male oriented might encourage female bus drivers to adopt a more masculine gender role and to minimize their emotional reactions, which then may have contributed to the reduced PTSD symptoms among female drivers. With the implementation and enforcement of equal employment opportunity policy in recent years, there will be more and more female employees entering traditionally male-dominant occupations, and vice versa. In order to thoroughly understand the reasons for gender differences in PTSD related to workplace violence, future studies should consider comparing levels of PTSD symptoms among participants who are working in traditionally gender 
specific occupations, such as male nurses and female bus drivers. Cross comparisons between male drivers versus male nurses or female drivers versus female nurses will prove fruitful in separating the gender role effects from biological sex effects on PTSD 5 .

Finally, according to our results, passenger initiated workplace violence appears to be very common among bus drivers. It is important for organizations to regularly analyze and survey employees' knowledge regarding workplace violence policies in the organization (Dillon, 2012) in order to create a safe and open environment for victims to use appropriate services effectively to overcome their psychological and work difficulties after encountering workplace violence. Trainees and students from high risk professions, such as bus drivers, police officers and healthcare workers, should learn about workplace violence and related policies in their work sector before they enter the profession and during orientation training.

\footnotetext{
${ }^{5}$ The participating public transit company has less than $25 \%$ female employees (including bus drivers, administrative staff, office workers and technicians, etc.) according to their latest public record, which may be considered a limitation of the current study. However, the gender distribution of bus drivers in this company was not available to the researchers at the time the study was conducted. With the company's effort to implement equal employment opportunity policy, the gender distribution of bus drivers could be changing drastically with more and more female bus drivers being presence in this occupation. Therefore, more research focusing on gender differences among bus drivers will be crucial to reflect a growing population of female bus drivers.
} 


\section{References}

Abbey, A., Abramis, D. J., \& Caplan, R. D. (1985). Effects of different sources of social support and social conflict on emotional well-being. Basic and Applied Social Psychology, 6(2), 111-129. doi: 10.1207/s15324834basp0602_2

Adams, R. E., \& Boscarino, J. A. (2006). Predictors of PTSD and delayed PTSD after disaster. The Journal of Nervous and Mental Disease, 194(7), 485-493. doi: 10.1097/01.nmd.0000228503.95503.e9

American Psychiatric Association. (1994). Diagnostic and statistical manual of mental disorders (4th ed.). Washington, DC.

American Psychiatric Association. (2013). Diagnostic and statistical manual of mental disorders (5th ed.). Washington, DC.

Andrews, B., Brewin, C. R., \& Rose, S. (2003). Gender, social support, and PTSD in victims of violent crime. Journal of Traumatic Stress, 16(4), 421-427. doi: 10.1023/a:1024478305142

Avery, M. L., \& McDevitt-Murphy, M. E. (2014). Impact of combat and social support on PTSD and alcohol consumption in OEF/OIF veterans. Military Behavioral Health, 2(2), 217-223. doi: 10.1080/21635781.2014.891433

Banyard, V., Potter, S., \& Turner, H. (2011). The impact of interpersonal violence in adulthood on women's job satisfaction and productivity: The mediating roles of mental and physical health. Psychology of Violence, 1(1), 16-28. doi: 10.1037/a0021691

Barbee, A. P., Cunningham, M. R., Winstead, B. A., Derlega, V. J., Gulley, M. R., Yankeelov, P. A., \& Druen, P. B. (1993). Effects of gender role expectations on the social support process. Journal of Social Issues, 49(3), 175-190. doi: 10.1111/j.1540-4560.1993.tb01175.x

Barling, J., Dupré, K. E., \& Kelloway, E. K. (2009). Predicting Workplace Aggression and Violence. Annual Review of Psychology, 60(1), 671-692. doi: 10.1146/annurev.psych.60.110707.163629 
Bliese, P. D., Wright, K. M., Adler, A. B., Cabrera, O., Castro, C. A., \& Hoge, C. W. (2008). Validating the primary care posttraumatic stress disorder screen and the posttraumatic stress disorder checklist with soldiers returning from combat. Journal of Consulting and Clinical Psychology, 76(2), 272-281. (PCL) doi: 10.1037/0022-006x.76.2.272

Borja, S. E., Callahan, J. L., \& Long, P. J. (2006). Positive and negative adjustment and social support of sexual assault survivors. Journal of Traumatic Stress, 19(6), 905-914. doi: $10.1002 /$ jts.20169

Boyer, R., \& Brunet, A. (1996). Prévalence du trouble de stress post-traumatique chez des chauffeurs d'autobus [Prevalence of post-traumatic stress disorder in bus drivers]. Santé mentale au Québec, 21(1), 189-208. doi: 10.7202/032387ar

Breslau, N., Lucia, V. C., \& Davis, G. C. (2004). Partial PTSD versus full PTSD: an empirical examination of associated impairment. Psychological Medicine, 34(7), 1205-1214. doi: 10.1017/s0033291704002594

Brewin, C. R., Andrews, B., Rose, S., \& Kirk, M. (1999). Acute stress disorder and posttraumatic stress disorder in victims of violent crime. American Journal of Psychiatry, 156(3), 360-366.

Brewin, C. R., Andrews, B., \& Valentine, J. D. (2000). Meta-analysis of risk factors for posttraumatic stress disorder in trauma-exposed adults. Journal of Consulting and Clinical Psychology, 68(5), 748-766. doi: 10.1037/0022-006X.68.5.748

Brunet, A., Boyer, R., Brillon, P., Ehrensaft, E., \& Stephenson, R. (1998). Lifetime exposure to traumatic events among a sample of city bus drivers. Psychological Reports, 83(3), 1155-1160. doi: 10.2466/pr0.1998.83.3f.1155

Brunet, A., Boyer, R., Weiss, D. S., \& Marmar, C. R. (2001). The effects of initial trauma exposure on the symptomatic response to a subsequent trauma. Canadian Journal of Behavioural Science/Revue canadienne des Sciences du comportement, 33(2), 97-102. doi: $10.1037 / \mathrm{h} 0087132$

Bryant, R. A., \& Harvey, A. G. (2003). Gender differences in the relationship between acute 
stress disorder and posttraumatic stress disorder following motor vehicle accidents. Australian and New Zealand Journal of Psychiatry, 37(2), 226-229. doi: 10.1046/j.1440-1614.2003.01130.x

Bryant, R. A., Moulds, M. L., \& Guthrie, R. M. (2000). Acute stress disorder scale: A self-report measure of acute stress disorder. Psychological Assessment, 12(1), 61-68. doi: $10.1037 / 1040-3590.12 .1 .61$

Budd, T. (2001, July). Violence at work: New findings from the 2000 British Crime Survey. Retrieved from http://www.hse.gov.uk/violence/britishcrimesurvey.pdf

Cable, N., Bartley, M., Chandola, T., \& Sacker, A. (2012). Friends are equally important to men and women, but family matters more for men's well-being. Journal of Epidemiology 6 Community Health, 67(2), 166-171. doi: 10.1136/jech-2012-201113

Cahill, S., Pontoski, K., \& D’Olio, C. (2005). Posttraumatic stress disorder and acute stress disorder ii: Considerations for treatment and prevention. Psychiatry, 2(9), 34-46.

Canadian Urban Transit Assocation. (2014, December). Stopping violence against urban transit operators (No. 45). Retrieved from http://cutaactu.ca/sites/default/files/issue_paper_45_e.pdf

Clapp, J. D., \& Gayle Beck, J. (2009). Understanding the relationship between PTSD and social support: The role of negative network orientation. Behaviour Research and Therapy, 47(3), 237-244. doi: 10.1016/j.brat.2008.12.006

Couto, M. T., \& Lawoko, S. (2011). Burnout, workplace violence and social support among drivers and conductors in the road passenger transport sector in Maputo City, Mozambique. Journal of occupational health, 53(3), 214-221. doi: 10.1539/joh.L10102

Crevier, M. G., Marchand, A., Nachar, N., \& Guay, S. (2014). Overt social support behaviors: Associations with ptsd, concurrent depressive symptoms and gender. Psychological Trauma: Theory, Research, Practice, and Policy, 6(5), 519-526. doi: $10.1037 / \mathrm{a} 0033193$

Cutrona, C. E., Shaffer, P. A., Wesner, K. A., \& Gardner, K. A. (2007). Optimally matching 
support and perceived spousal sensitivity. Journal of Family Psychology, 21(4), 754-758. doi: 10.1037/0893-3200.21.4.754

Cutrona, C. E., \& Suhr, J. A. (1994). Social support communication in the context of marriage: An analysis of couples' supportive interactions. In B. R. Burleson, T. L. Albrecht, \& I. G. Sarason (Eds.), Communication of social support: Messages, interactions, relationships, and community (p. 113-135). Thousand Oaks, CA, US: Sage Publications, Inc.

Dickstein, B. D., Weathers, F. W., Angkaw, A. C., Nievergelt, C. M., Yurgil, K., Nash, W. P., .. Litz, B. T. (2014). Diagnostic utility of the posttraumatic stress disorder (PTSD) checklist for identifying full and partial PTSD in active-duty military. Assessment, 22(3), 289-297. doi: 10.1177/1073191114548683

Dillon, B. L. (2012). Workplace violence: Impact, causes, and prevention. Work, 42(1), 15-20. doi: 10.3233/WOR-2012-1322

Duffy, C. A., \& McGoldrick, A. E. (1990). Stress and the bus driver in the uk transport industry. Work \& Stress, 4(1), 17-27. doi: 10.1080/02678379008256961

Dupré, K. E., Dawe, K. A., \& Barling, J. (2014). Harm to those who serve: Effects of direct and vicarious customer-initiated workplace aggression. Journal of Interpersonal Violence, 29(13), 2355-2377. doi: 10.1177/0886260513518841

Essenberg, B. (2003). Violence and stress at work in the transport sector. Geneva: International Labour Office. Retrieved from http://siteresources. worldbank.org/INTTSR/Resources/wp205.pdf

Evans, G. W., \& Johansson, G. (1998). Urban bus driving: An international arena for the study of occupational health psychology. Journal of Occupational Health Psychology, 3(2), 99-108. doi: 10.1037/1076-8998.3.2.99

Evans, S., Giosan, C., Patt, I., Spielman, L., \& Difede, J. (2006). Anger and its association to distress and social/occupational functioning in symptomatic disaster relief workers responding to the September 11, 2001, world trade center disaster. Journal of 
Traumatic Stress, 19(1), 147-152. doi: 10.1002/jts.20107

French, S. A., Harnack, L. J., Hannan, P. J., Mitchell, N. R., Gerlach, A. F., \& Toomey, T. L. (2010). Worksite environment intervention to prevent obesity among metropolitan transit workers. Preventive Medicine, 50(4), 180-185. doi: 10.1016/j.ypmed.2010.01.002

Galdas, P. M., Cheater, F., \& Marshall, P. (2005). Men and health help-seeking behaviour: literature review. Journal of Advanced Nursing, 49(6), 616-623. doi: 10.1111/j.1365-2648.2004.03331.x

Gates, D. M., Gillespie, G. L., \& Succop, P. (2011). Violence against nurses and its impact on stress and productivity. Nursing Economics, 29(2), 59-66.

Gilbert, B. (2011). The nature of occupational violence against taxicab drivers: Violence against taxicab drivers. Public Health Nursing, 28(4), 335-348. doi: 10.1111/j.1525-1446.2011.00944.x

Glaso, L., Bele, E., Nielsen, M. B., \& Einarsen, S. (2011). Bus drivers' exposure to bullying at work: An occupation-specific approach. Scandinavian Journal of Psychology, 52(5), 484-493. doi: 10.1111/j.1467-9450.2011.00895.x

Gradus, J. L. (2016). Epidemiology of PTSD. Retrieved from http://www.ptsd.va.gov/professional/PTSD-overview/epidemiological-facts-ptsd.asp

Guay, S., Beaulieu-Prevost, D., Beaudoin, C., St-Jean-Trudel, E., Nachar, N., Marchand, A., \& O'connor, K. P. (2011). How do social interactions with a significant other affect PTSD symptoms? An empirical investigation with a clinical sample. Journal of Aggression, Maltreatment \& Trauma, 20(3), 280-303. doi: $10.1080 / 10926771.2011 .562478$

Guay, S., Billette, V., \& Marchand, A. (2006). Exploring the links between posttraumatic stress disorder and social support: Processes and potential research avenues. Journal of Traumatic Stress, 19(3), 327-338. doi: 10.1002/jts.20124 
Guay, S., Goncalves, J., \& Jarvis, J. (2014). Verbal violence in the workplace according to victims' sex - systematic review of the literature. Aggression and Violent Behavior, 19(5), 572-578. doi: 10.1016/j.avb.2014.08.001

Harrell, E. (2011). Workplace violence, 1993-2009 (Tech. Rep. No. NCJ233231). US Department of Justice, Office of Justice Programs, Bureau of Justice Statistics. Retrieved from http://www.bjs.gov/index. cfm?ty=pbdetail\&iid=2377

Harvey, A. G., \& Bryant, R. A. (2000). Two-year prospective evaluation of the relationship between acute stress disorder and posttraumatic stress disorder following mild traumatic brain injury. American Journal of Psychiatry, 157(4), 626-628.

Health and Safty Executive. (2015). Violence at work 2013/14. National Statistics. Retrieved from www.hse.gov.uk/statistics/

Hershcovis, M. S., \& Barling, J. (2007). Towards a relational model of workplace aggression. In J. Langan-Fox, C. L. Cooper, \& R. Klimoski (Eds.), Dysfunctional Workplace: Management Challenges and Symptoms (pp. 268-284). Cheltenham, UK: Edward Elgar Publishing Ltd.

Joseph, S., Williams, R., \& Yule, W. (1997). Understanding post-traumatic stress: A psychosocial perspective on PTSD and treatment. Chichester, England: John Wiley \& Sons Inc.

Kessler, R., Berglund, P., Delmer, O., Jin, R., Merikangas, K., \& Walters, E. (2005). Lifetime prevalence and age-of-onset distributions of DSM-IV disorders in the National Comorbidity Survey Replication. Archives of General Psychiatry, 62(6), 593-602. doi: 10.1001/archpsyc.62.6.593

Kompier, M. A. J., Aust, B., van den Berg, A.-M., \& Siegrist, J. (2000). Stress prevention in bus drivers: Evaluation of 13 natural experiments. Journal of Occupational Health Psychology, 5(1), 11-31. doi: 10.1037//1076-8998.5.1.11

Kunst, M. J. J., \& Winkel, F. W. (2013). Exploring the impact of dysfunctional posttraumatic survival responses on crime revictimization. Violence and Victims, 
28(4), 670-680. doi: 10.1891/0886-6708.vv-d-12-00035

Kunst, M. J. J., Winkel, F. W., \& Bogaerts, S. (2011). Posttraumatic anger, recalled peritraumatic emotions, and PTSD in victims of violent crime. Journal of Interpersonal Violence, 26(17), 3561-3579. doi: 10.1177/0886260511403753

Laffaye, C., Cavella, S., Drescher, K., \& Rosen, C. (2008). Relationships among PTSD symptoms, social support, and support source in veterans with chronic PTSD. Journal of Traumatic Stress, 21(4), 394-401. doi: 10.1002/jts.20348

Lakey, B., Tardiff, T. A., \& Drew, J. B. (1994). Negative social interactions: Assessment and relations to social support, cognition, and psychological distress. Journal of Social and Clinical Psychology, 13(1), 42-62. doi: 10.1521/jscp.1994.13.1.42

Lanctôt, N., \& Guay, S. (2014). The aftermath of workplace violence among healthcare workers: A systematic literature review of the consequences. Aggression and Violent Behavior, 19(5), 492-501. doi: 10.1016/j.avb.2014.07.010

LeBlanc, M. M., \& Barling, J. (2005). Understanding many faces of workplace violence. In S. Fox \& P. E. Spector (Eds.), Counterproductive work behavior: Investigations of actors and targets (pp. 41-63). Washington, DC: American Psychological Association.

Lerias, D., \& Byrne, M. K. (2003). Vicarious traumatization: symptoms and predictors. Stress and Health, $19(3)$, 129-138. doi: 10.1002/smi.969

Lilly, M. M., Pole, N., Best, S. R., Metzler, T., \& Marmar, C. R. (2009). Gender and PTSD: What can we learn from female police officers? Journal of Anxiety Disorders, 23(6), 767-774. doi: 10.1016/j.janxdis.2009.02.015

Lincoln, R., \& Gregory, A. (2015). Moving violations: A study of incivility and violence against urban bus drivers in Australia. International Journal of Education and Social Science, 2(1), 118-127.

Martin, T., \& Daffern, M. (2006). Clinician perceptions of personal safety and confidence to manage inpatient aggression in a forensic psychiatric setting. Journal of Psychiatric and Mental Health Nursing, 13(1), 90-99. (CCPAI) doi: 
$10.1111 / \mathrm{j} .1365-2850.2006 .00920 . x$

Matthews, L. R., \& Chinnery, D. (2005). Prediction of work functioning following accidental injury: The contribution of PTSD symptom severity and other established risk factors. International Journal of Psychology, 40(5), 339-348. doi: 10.1080/00207590444000320

Mayhew, C. (2000). Violent assaults on taxi drivers: Incidence patterns and risk factors. (178). Retrieved from http://www.aic.gov.au/media_library/publications/tandi_pdf/tandi178.pdf

Obelenis, V., Gedgaudiene, D., \& Vasilavicius, P. (2003). Working conditions and health of the employees of public bus and trolleybus transport in Lithuania. Medicina, 39(11), 1103-1109. Retrieved 2016-02-10, from https://www.ncbi.nlm.nih.gov/pubmed/14646466

Olff, M., Langeland, W., Draijer, N., \& Gersons, B. P. R. (2007). Gender differences in posttraumatic stress disorder. Psychological Bulletin, 133(2), 183-204. doi: 10.1037/0033-2909.133.2.183

Ozer, E. J., Best, S. R., Lipsey, T. L., \& Weiss, D. S. (2008). Predictors of posttraumatic stress disorder and symptoms in adults: A meta-analysis. Psychological Trauma: Theory, Research, Practice, and Policy, S(1), 3-36. doi: 10.1037/1942-9681.s.1.3

Pietrzak, R. H., Johnson, D. C., Goldstein, M. B., Malley, J. C., Rivers, A. J., Morgan, C. A., \& Southwick, S. M. (2010). Psychosocial buffers of traumatic stress, depressive symptoms, and psychosocial difficulties in veterans of operations enduring freedom and Iraqi freedom: The role of resilience, unit support, and postdeployment social support. Journal of Affective Disorders, 120(1-3), 188-192. doi: 10.1016/j.jad.2009.04.015

Pole, N., Best, S. R., Weiss, D. S., Metzler, T., Liberman, A. M., Fagan, J., \& Marmar, C. R. (2001). Effects of gender and ethnicity on duty-related posttraumatic stress symptoms among urban police officers. The Journal of Nervous and Mental Disease, 189(7), 
442-448. doi: 10.1097/00005053-200107000-00005

Rusbult, C. E., \& Van Lange, P. A. M. (2008). Why we need interdependence theory. Social and Personality Psychology Compass, 2(5), 2049-2070. doi:

10.1111/j.1751-9004.2008.00147.x

Rydstedt, L. W., Johansson, G., \& Evans, G. W. (1998). A longitudinal study of workload, health and well-being among male and female urban bus drivers. Journal of Occupational and Organizational Psychology, 71(1), 35-45. doi: 10.1111/j.2044-8325.1998.tb00661.x

Sampaio, R. F., Coelho, C. M., Barbosa, F. B., Mancini, M. C., \& Parreira, V. F. (2009). Work ability and stress in a bus transportation company in Belo Horizonte, Brazil. Ciênc ES Saúde Coletiva, 14(1), 287-296. doi: 10.1590/S1413-81232009000100035

Schnurr, P. P., Lunney, C. A., \& Sengupta, A. (2004). Risk factors for the development versus maintenance of posttraumatic stress disorder. Journal of Traumatic Stress, 17(2), 85-95. doi: 10.1023/b:jots.0000022614.21794.f4

Shumaker, S. A., \& Hill, D. R. (1991). Gender differences in social support and physical health. Health, 10(2), 102-111. doi: 10.1037/0278-6133.10.2.102

Singer, J. D., \& Willett, J. B. (2003). Applied longitudinal data analysis: Modeling change and event occurrence. Oxford University Press.

Smith, M., \& Cornish, D. (Eds.). (2006). Secure and tranquil travel: preventing crime and disorder on public transport. London: Routledge.

Stein, M. B., Walker, J. R., \& Forde, D. R. (2000). Gender differences in susceptibility to posttraumatic stress disorder. Behaviour Research and Therapy, 38(6), 619-628. doi: $10.1016 /$ s0005-7967(99)00098-4

Taylor, S., Wald, J., \& Asmundson, G. J. (2006). Factors associated with occupational impairment in people seeking treatment for posttraumatic stress disorder. Canadian Journal of Community Mental Health, 25(2), 289-301. doi: 10.7870/cjcmh-2006-0026

Thackrey, M. (1987). Clinician confidence in coping with patient aggression: Assessment and 
enhancement. Professional Psychology: Research and Practice, 18(1), 57-60. doi: $10.1037 / 0735-7028.18 .1 .57$

The Department of Justice Canada. (2015). Government of Canada celebrates legislation to ensure the safety and security of hardworking public transit operators [Press Release]. Retrieved from http://news.gc.ca/web/article-en.do?nid=953849

Tolin, D. F., \& Foa, E. B. (2006). Sex differences in trauma and posttraumatic stress disorder: A quantitative review of 25 years of research. Psychological Bulletin, 132(6), 959-992. doi: 10.1037/0033-2909.132.6.959

Tse, J. L., Flin, R., \& Mearns, K. (2006). Bus driver well-being review: 50 years of research. Transportation Research Part F: Traffic Psychology and Behaviour, 9(2), 89-114. doi: 10.1016/j.trf.2005.10.002

Van Ameringen, M., Mancini, C., Patterson, B., \& Boyle, M. H. (2008). Post-traumatic stress disorder in Canada. CNS Neuroscience 8 Therapeutics, 14 (3), 171-181. doi: $10.1111 / \mathrm{j} .1755-5949.2008 .00049 . x$

Vedantham, K., Brunet, A., Boyer, R., Weiss, D., Metzler, T., \& Marmar, C. (2001). Posttraumatic stress disorder, trauma exposure, and the current health of canadian bus drivers. Canadian Journal of Psychiatry, 46(2), 149-155. doi: $10.1177 / 070674370104600206$

Verhaeghe, S., Duprez, V., Beeckman, D., Leys, J., Meijel, B. V., \& Hecke, A. V. (2014). Mental health nurses' attitudes and perceived self-efficacy toward inpatient aggression: A cross-sectional study of associations with nurse-related characteristics. Perspect Psychiatr Care, 52(1), 12-24. doi: 10.1111/ppc.12097

Weathers, F., Litz, B., Herman, D., Huska, J., \& Keane, T. (1993). The PTSD checklist (PCL): Reliability, validity, and diagnostic utility. San Antonio, TX.

Wickham, R. E., \& Knee, C. R. (2012). Interdependence theory and the actor-partner interdependence model: Where theory and method converge. Personality and Social Psychology Review, 16(4), 375-393. doi: 10.1177/1088868312447897 
Work Safe BC. (n.d.). Work impairment and limitations associated with posttraumatic stress disorder. Retrieved from http://www.worksafebc.com

Yehuda, R. (2002). Post-traumatic stress disorder. New England Journal of Medicine, 346(2), 108-114. doi: 10.1056/nejmra012941

Zlotnick, C., Franklin, C., \& Zimmerman, M. (2002). Does "subthreshold" posttraumatic stress disorder have any clinical relevance? Comprehensive Psychiatry, 43(6), 413-419. doi: $10.1053 /$ comp.2002.35900 
Table 1

Participants meeting PTSD Diagnostics at Each Time Assessment

\begin{tabular}{lcccc}
\hline & Time 1 & Time 2 & Time 3 & Time 4 \\
\hline Full Sample & & & & \\
Acute Stress Disorder & $58.7 \%$ & - & - & - \\
Full PTSD & - & $17.4 \%$ & $12.0 \%$ & $5.7 \%$ \\
Partial PTSD & - & $22.9 \%$ & $16.7 \%$ & $15.4 \%$ \\
Moderate Problems in PTSD & - & $44.0 \%$ & $20.4 \%$ & $24.0 \%$ \\
Total Percentage & $58.7 \%$ & $84.3 \%$ & $49.1 \%$ & $45.1 \%$ \\
& & & & \\
Men & & & & \\
Acute Stress Disorder & $60.3 \%$ & - & - & - \\
Full PTSD & - & $19.0 \%$ & $14.3 \%$ & $6.7 \%$ \\
Partial PTSD & - & $20.6 \%$ & $17.5 \%$ & $10.0 \%$ \\
Moderate Problems in PTSD* & - & $52.4 \%{ }^{a}$ & $19.0 \%$ & $23.3 \%$ \\
Total Percentage & $60.3 \%$ & $92.0 \%$ & $50.8 \%$ & $40.0 \%$ \\
& & & & \\
Women & & & & \\
Acute Stress Disorder & $56.5 \%$ & - & - & - \\
Full PTSD & - & $15.2 \%$ & $8.9 \%$ & $4.5 \%$ \\
Partial PTSD & - & $37.0 \%$ & $15.6 \%$ & $20.5 \%$ \\
Moderate Problems in PTSD* & - & $32.6 \%{ }^{a}$ & $22.2 \%$ & $25.0 \%$ \\
Total Percentage & $56.5 \%$ & $84.8 \%$ & $46.7 \%$ & $50.0 \%$ \\
\hline Note * Significant & & & & \\
\hline
\end{tabular}

Note. ${ }^{*}$ Significant gender differences. 


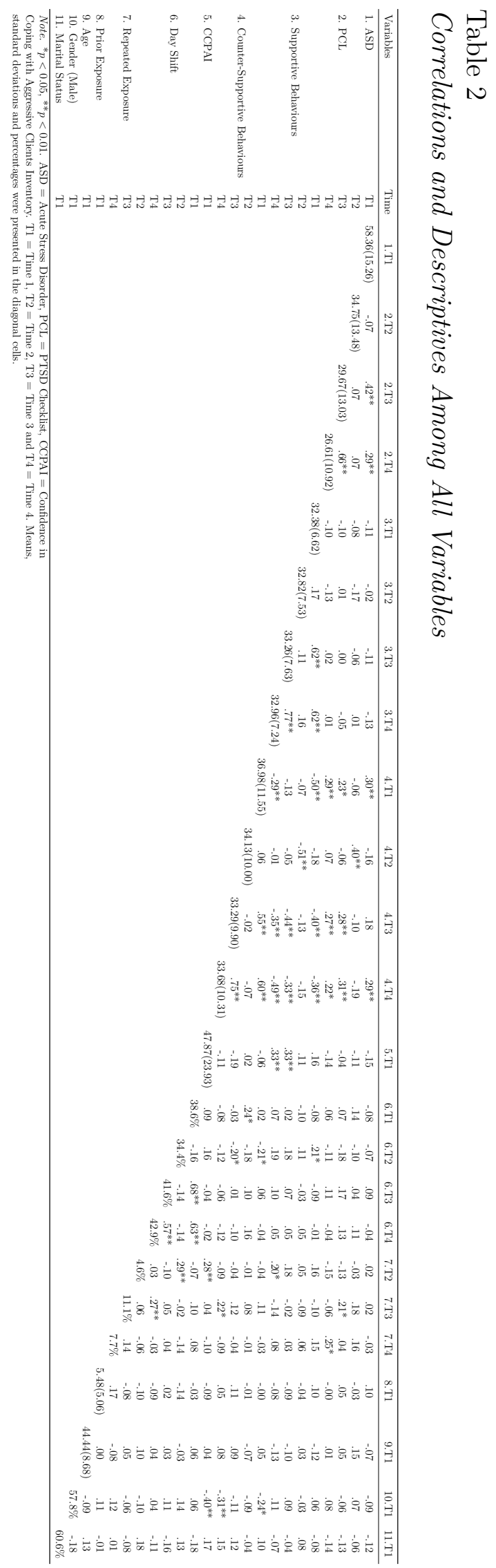




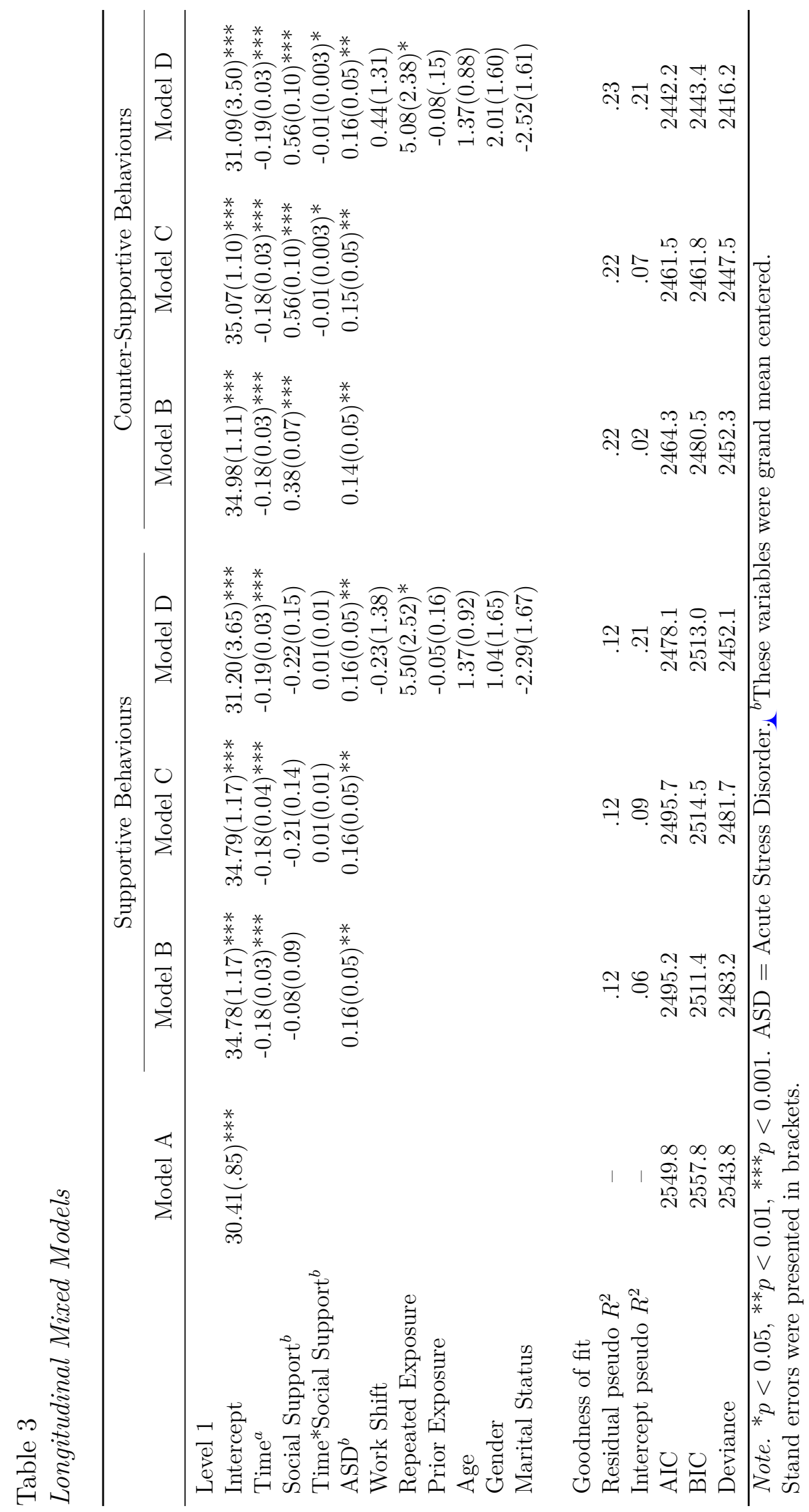


Table 4

Multiple Regression Model for Predicting Confidence in Coping with Aggressive Passengers

\begin{tabular}{|c|c|c|c|c|c|c|}
\hline & $B$ & $S E$ & $t$ & Partial $r$ & $F$ & $R^{2}$ \\
\hline Step 1 & & & & & $18.06^{* * *}$ & 0.16 \\
\hline Intercept & 56.07 & 2.95 & $19.01^{* * *}$ & & & \\
\hline Gender & -19.14 & 4.51 & $-4.25 * * *$ & -0.40 & & \\
\hline Step 2 & & & & & $11.39 * * *$ & 0.19 \\
\hline Intercept & 73.32 & 8.97 & $8.17^{* * *}$ & & & \\
\hline Gender & -20.08 & 4.46 & $-4.51^{* * *}$ & -0.42 & & \\
\hline ASD & -0.29 & 0.14 & $-2.03^{*}$ & -0.19 & & \\
\hline Step 3 & & & & & $4.88^{* *}$ & 0.21 \\
\hline Intercept & 81.28 & 11.29 & $7.20 * * *$ & & & \\
\hline Gender & -19.33 & 4.56 & $-4.24^{* * *}$ & -0.40 & & \\
\hline ASD & -0.34 & 0.16 & $-2.09^{*}$ & -0.19 & & \\
\hline Time 2 PTSD & -0.18 & 0.16 & -1.11 & -0.12 & & \\
\hline Time 3 PTSD & 0.20 & 0.24 & 0.81 & 0.08 & & \\
\hline Time 4 PTSD & -0.19 & 0.27 & -0.71 & -0.07 & & \\
\hline
\end{tabular}

Disorder. 


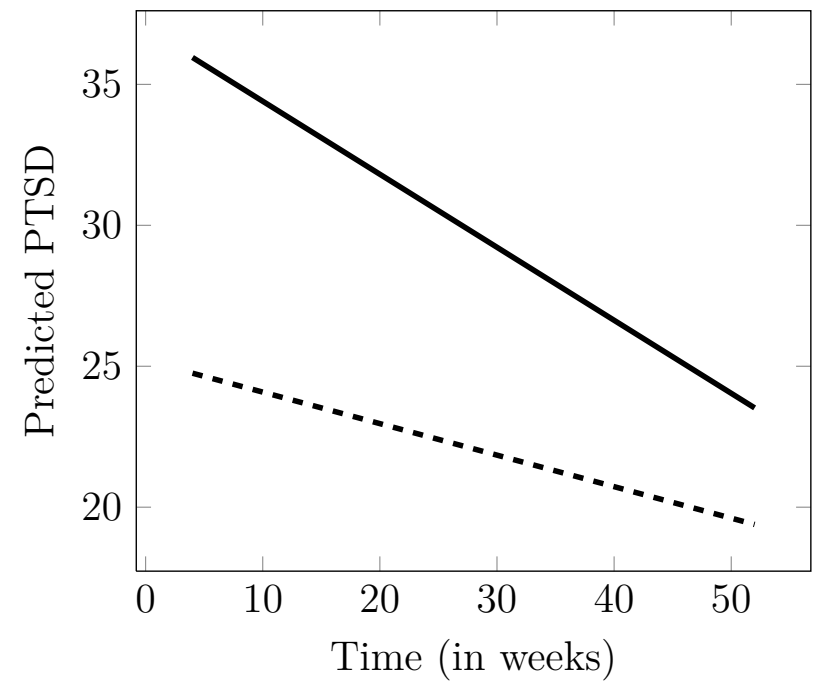

Figure 1. Counter-Supportive Behaviours. - High Counter-Supportive Behaviours, -.. Low Counter-Supportive Behaviours. 